\title{
Comparison of (6S)-5-methyltetrahydrofolic acid $v$. folic acid as the reference folate in longer-term human dietary intervention studies assessing the relative bioavailability of natural food folates: comparative changes in folate status following a 16-week placebo-controlled study in healthy adults
}

\author{
Anthony J. A. Wright ${ }^{1 *}$, Maria J. King ${ }^{1}$, Caroline A. Wolfe ${ }^{1}$, Hilary J. Powers ${ }^{2}$ and Paul M. Finglas ${ }^{1}$ \\ ${ }^{1}$ Institute of Food Research, Norwich Research Park, Colney, Norwich NR4 7UA, UK \\ ${ }^{2}$ Human Nutrition Unit, University of Sheffield, The School of Medicine, Sheffield S1O 2RX, UK \\ (Received 1 April 2009 - Revised 28 July 2009 - Accepted 28 July 2009 - First published online 26 October 2009)
}

Folic acid (pteroylmonoglutamic acid) has historically been used as the reference folate in human intervention studies assessing the relative bioavailability of dietary folate. Recent studies using labelled folates indicated different plasma response kinetics to folic acid than to natural (food) folates, thus obviously precluding its use in single-dose experiments. Since differences in tissue distribution and site of biotransformation were hypothesised, the question is whether folic acid remains suitable as a reference folate for longer-term intervention studies, where the relative bioavailability of natural (food) folate is assessed based on changes in folate status. Healthy adults aged 18-65 years ( $n$ 163) completed a 16-week placebo-controlled intervention study in which the relative bioavailability of increased folate intake ( $453 \mathrm{nmol} / \mathrm{d})$ from folate-rich foods was assessed by comparing changes in plasma and erythrocyte folate concentration with changes induced by an equal reference dose of supplemental (6S)-5-methyltetrahydrofolic acid or folic acid. The relative increase in plasma folate concentration in the food group was $31 \%$ when compared with that induced by folic acid, but $39 \%$ when compared with (6S)-5-methyltetrahydrofolic acid. The relative increase in erythrocyte folate concentration in the food group when compared with that induced by folic acid was $43 \%$, and $40 \%$ when compared with $(6 S)$-5-methyltetrahydrofolic acid. When recent published observations were additionally taken into account it was concluded that, in principle, folic acid should not be used as the reference folate when attempting to estimate relative natural (food) folate bioavailability in longer-term human intervention studies. Using (6S)-5-methyltetrahydrofolic acid as the reference folate would avoid future results' validity being questioned.

Human nutrition: (6S)-5-methyltetrahydrofolic acid: Folic acid: Plasma homocysteine: Folate: Bioavailability: Intervention studies

Low folate status is associated with increased risk of neural tube defects in the developing fetus and raising maternal folate status before conception and during pregnancy has been shown to reduce occurrence by approximately $70 \%{ }^{(1)}$. Additionally, low folate status has been associated with increased risk of other disease states in adults, such as $\mathrm{CVD}^{(2)}$, dementia ${ }^{(3)}$ and some cancers ${ }^{(4)}$. In the UK, fortification of foods with folate, normally in the form of folic acid, is optional. In some countries, such as the USA, Chile and Canada, a mandatory programme where all flour is fortified with folic acid has been in place for some time ${ }^{(5-7)}$, and is currently under consideration in the UK.

Folate status can be raised either by supplementation or fortification (usually with folic acid), or by increasing consumption of folate-rich foods. Whilst some countries have introduced policies of mandatory fortification, many have not. Those countries without mandatory fortification are thus either dependent mainly on natural food folates to optimise status, or on a mix of natural food folates and voluntary supplementation and/or optional food fortification. Since, for a variety of reasons, folate bioavailability from food is lower than folic acid ${ }^{(8)}$ it is important to be able to assess this in order to make evidence-based recommendations for dietary intake. The assessment of folate bioavailability from whole diets, rather than single foods, has been highlighted as of high priority by a UK Food Standards Agency workshop report $^{(9)}$.

Since, following transfer of folate from the gut mucosal cells, there is extensive but unquantified removal of newly absorbed folate from the hepatic portal vein (liver 'firstpass') ${ }^{(10)}$, absolute absorption cannot be estimated. Instead, in an attempt to circumvent this problem, single-dose experimental protocols estimate 'relative absorption' from a test dose by comparison with a similar reference dose of folic acid. Whilst short-term single-dose acute protocols involve monitoring the appearance and subsequent clearance of the (6S)-5-methyltetrahydrofolic acid $\left(5-\mathrm{CH}_{3} \mathrm{H}_{4} \mathrm{PteGlu}\right)$ response in the fast turnover plasma or serum pool arising from absorbed and biotransformed oral test folates, longer-term chronic dietary intervention protocols assessing 'relative

Abbreviations: 5- $\mathrm{CH}_{3} \mathrm{H}_{4}$ PteGlu, (6S)-5-methyltetrahydrofolic acid; RNI, UK reference nutrient intake.

* Corresponding author: Dr Anthony J. A. Wright, fax +44 1603 507723, email tony.wright@bbsrc.ac.uk 
bioavailability' involve monitoring changes in markers of folate status (plasma or serum folate, erythrocyte folate $)^{(8,11)}$. Plasma or serum folate is the most responsive indicator, with changes in erythrocyte folate responding more slowly because $<1 \%$ of circulating erythrocytes are replaced daily ${ }^{(11)}$. Hence, studies wishing to monitor optimal changes in participants' erythrocyte folate concentrations should have a duration of at least 16 weeks to ensure a turnover of erythrocytes whose average life-span is $120 \mathrm{~d}$.

Our recent studies using labelled folates indicated different plasma response kinetics to folic acid than to natural (food) folates, obviously precluding its use for estimating 'relative absorption' in single-dose studies ${ }^{(12,13)}$. Since we hypothesised differences in tissue distribution and site of biotransformation $^{(13,14)}$, the question is whether folic acid remains suitable as a reference folate for longer-term intervention studies, where 'relative bioavailability' of natural (food) folate is assessed based on changes in folate status.

If, as we hypothesised, absorbed folic acid leads to the more rapid accumulation of liver folate stores compared with other absorbed natural (food) folates, it could be further inferred that the use of folic acid as a reference in longer-term feeding studies may at the very least lead to a comparatively accelerated change in plasma or serum folate concentration in fasting blood since this is a function of enterohepatic recirculation (estimated at $60-227 \mathrm{nmol} / \mathrm{d}^{(15,16)}$ ) which increases in proportion to the magnitude of liver stores $^{(17)}$. Thus, comparison of the change in fasting plasma or serum folate induced by natural food or nature-identical folate to the change in fasting plasma or serum folate induced by folic acid may result in the significant underestimation of 'relative bioavailability'. We have suggested previously that folic acid could be replaced as a reference folate by $5-\mathrm{CH}_{3} \mathrm{H}_{4} \mathrm{PteGlu}{ }^{(14)}$, the natural form of folate found in the systemic circulating blood system.

Here we test this hypothesis using a partially doubleblinded, placebo-controlled, nutritional intervention study in apparently healthy adults, which was part of a larger investigation into the effects of folate on biomarkers of cardiovascular risk, in collaboration with the University of Sheffield. In the present paper we assess the relative bioavailability of increased folate intake from naturally folate-rich foods by comparison of changes in plasma and erythrocyte folate concentration with changes induced by an equal reference dose of either supplemental $5-\mathrm{CH}_{3} \mathrm{H}_{4} \mathrm{PteGlu}$ or folic acid. The choice of a 'physiological' intervention dose is important since it is known that there is a threshold for the postprandial appearance of unmetabolised folic acid in the systemic blood system. When previously using an oral dose of $634 \mathrm{nmol}$ $\left.(280 \mu \mathrm{g}){ }_{[13}^{13} \mathrm{C}_{6}\right]$ folic acid with liquid chromatography-MS analysis $^{(12,13)}$, we found no detectable folic acid in the postprandial plasma response; this observation is in line with a previous observation using liquid chromatographymicrobiological assay analysis that the threshold was above $603 \mathrm{nmol}(266 \mu \mathrm{g})^{(18)}$. In contrast, a recent report using a more sensitive version of the liquid chromatographymicrobiological assay procedure concluded that the threshold for folic acid is about $453 \mathrm{nmol}(200 \mu \mathrm{g})^{(19)}$. In the present study we employed the lower dose of $453 \mathrm{nmol}(200 \mu \mathrm{g})$, thus ensuring results could be interpreted independently of threshold effects.

\section{Methods}

\section{Study design}

Ethical approval was obtained from the Norfolk 1 Research Ethics Committee following review by the Institute of Food Research's Human Research Governance Committee and the East Norfolk and Waveney Research Governance Committee.

Generally healthy males and females aged 18-65 years were recruited initially from the database for volunteers held at the Institute of Food Research's Human Nutrition Unit based on their eligibility for the study. Volunteers were also recruited through advertisements in the media, recruitment stands, email adverts, posters or word-of-mouth. Exclusion criteria for the study were as follows: females that were pregnant or had been pregnant within 12 months of commencement of the study, females that were breast-feeding, anyone who had donated or intended to donate blood within 16 weeks of the first or last study samples, BMI $<18$ or $>40 \mathrm{~kg} / \mathrm{m}^{2}$, receiving vascular disease or anti-hypertensive drugs, those with diabetes, and anyone taking $\mathrm{B}$ vitamin or folic acid supplements on a regular basis (including multivitamin supplements). Supplement users willing to stop supplements for the study were able to participate following a minimum $120 \mathrm{~d}$ washout period before pre-study screening.

Potential participants were invited to a pre-study interview before signing consent. Informed consent was obtained at screening. Volunteers were asked to complete a health questionnaire with a research nurse, who also recorded blood pressure, height and weight (from which BMI was calculated). A first-of-the-day midstream urine sample was provided by the volunteer for a dipstick test (Combur 9 Test ${ }^{\circledR}$; Roche Diagnostics Ltd, Burgess Hill, West Sussex, UK); pH, protein, glucose, ketones, urobilinogen, bilirubin, blood, leucocytes, nitrites) and, if satisfactory, a $5 \mathrm{ml}$ fasted blood sample was then taken for full blood count analysis (SPIRE hospital laboratory, Colney, Norwich). Volunteers with satisfactory urinalysis results and full blood counts within the standard reference ranges were accepted on to the study. Blood results outside the normal reference range were assessed by the medical advisor to the Institute of Food Research's Human Nutrition Unit. Excluded volunteers were notified by telephone of the screening outcomes, and their general practitioners notified by letter.

Once accepted on to the study, volunteers were allocated to one of four intervention groups by a senior staff member unconnected to the study. Volunteers participated in a 16-week dietary intervention 4-6 weeks after screening, during which they consumed in addition to their normal diets either (a) an additional $453 \mathrm{nmol}$ natural food folate per $\mathrm{d}$ (from a selection of folate-rich foods), (b) a gelatin capsule containing supplemental $5-\mathrm{CH}_{3} \mathrm{H}_{4} \mathrm{PteGlu}$ (Metafolin ${ }^{\circledR}$; $453 \mathrm{nmol}$ ), (c) a gelatin capsule containing supplemental folic acid (453 nmol; $200 \mu \mathrm{g}$ ), or (d) a gelatin placebo capsule. Naturally folate-rich foods for the food intervention group were selected from the McCance \& Widdowson 6th edition $^{(20)}$. High-folate foods with manageable portion sizes were selected and drawn into a choice list for the volunteer. A wide range of foods was available in the choice list, and included: vegetables such as spinach, Brussels sprouts, broccoli, peas, asparagus, cauliflower; cereals such as granary bread and non-fortified muesli; dairy products such as 
camembert, brie and cheddar cheese; and grocery items such as baked beans, orange juice, liver pâté, vegetable pâté and mixed nuts. Each food was given a unit value (where one unit $=113.25 \mathrm{nmol}$ folate) and the volunteers asked to consume four units/d to achieve $453 \mathrm{nmol}$ folate from preweighed food portions, which were delivered to them weekly. The capsules were generously gifted to the project by Merck Eprova AG (Schaffhausen, Switzerland), and were delivered to volunteers every 4th week. Volunteers consumed one capsule within each $24 \mathrm{~h}$ period, at their own convenience. Capsules were coded, and the code not broken until the end of the study.

Volunteers provided a $12 \mathrm{~h}$ fasted blood sample on day 1 (baseline sample) and a second fasted blood sample the day immediately after the 16-week intervention period for plasma homocysteine and plasma and erythrocyte folate analyses. Samples of blood were also sent for full blood count (SPIRE hospital laboratory, Colney, Norwich); this was principally to obtain packed cell volumes required for the calculation of erythrocyte folate concentrations.

\section{Dietary assessment}

Dietary folate intakes were assessed by means of a $7 \mathrm{~d}$ (every third day) weighed food intake carried out in the month before, and during the last 4 weeks of the intervention phase. Records of foods consumed were coded and analysed by the nutritional software Diet Cruncher for Windows ${ }^{(}$ (WayDownSouth Software, Dunedin, New Zealand) using the UK dataset from McCance and Widdowson, version $6^{(20)}$.

\section{Analysis of folate and homocysteine}

Folate concentration in plasma and whole blood was determined using a chloramphenicol-resistant Lactobacillus rhamnosus NCIMB 10463 microbiological assay ${ }^{(21)}$ modified by haemolysis of whole blood by 10-fold dilution in $1 \%$ ascorbic acid pre-adjusted to $\mathrm{pH} 4 \cdot 25^{(22)}$. Erythrocyte folate concentration was calculated from whole-blood values using individual packed cell volumes and after correction for plasma folate concentration. Day-to-day precision of the method was closely monitored by including in each analytical run high (plasma mean 48.28 (SD 2.56) $\mathrm{nmol} / \mathrm{l}, \mathrm{CV} 5.3 \%$; erythrocyte folate mean 1049.5 (SD 42.5) nmol/l, CV 4.0\%), medium (plasma mean 22.63 (SD 1.70) nmol/l, CV 7.5\%; erythrocyte folate mean 379.9 (SD 17.7) nmol/l, CV 4.7\%) and low (plasma mean 8.54 (SD 0.68) nmol/l, CV 8.0\%; erythrocyte folate mean 148.8 (SD 16.2) $\mathrm{nmol} / \mathrm{l}, \mathrm{CV} 10.9 \%$ ) in-house quality controls from either plasma or whole-blood pools, as appropriate. Additionally, accuracy of the method was monitored monthly with the use of two external quality controls: WHO 1st Serum Folate International Standard IS 03/178 (assigned value $12.1 \mathrm{nmol} / 1$; mean 12.83 (SD 1.07) $\mathrm{nmol} / \mathrm{l}$, CV $8.3 \%$ ) and WHO 1st Whole Blood International Standard IS $95 / 528$ (assigned value $29.45 \mathrm{nmol} / 1$; mean 30.25 (SD 1.53) nmol/1, CV $5 \cdot 1 \%$ ). Plasma total homocysteine was determined by fluorescence polarisation immunoassay at the University of Sheffield, on an Abbott IMX automated analyser together with high, medium and low quality controls containing L-homocysteine in processed human serum (Abbott Diagnostics, Maidenhead, Berks, UK). Commercial quality controls provided with the kit were used to check precision. For the low control (assigned value $7 \cdot 0 \mu \mathrm{mol} / \mathrm{l}$ ) the mean was $7 \cdot 17 \mu \mathrm{mol} / 1$, intrabatch CV $2.2 \%$, interbatch CV $1.9 \%$. For the median control (assigned value $12.5 \mu \mathrm{mol} / \mathrm{l}$ ) the mean was $12.8 \mu \mathrm{mol} / \mathrm{l}$, intrabatch CV $1.9 \%$, interbatch CV $1.9 \%$. For the high control (assigned value $25 \mu \mathrm{mol} / \mathrm{l}$ ) the mean was $25.3 \mu \mathrm{mol} / \mathrm{l}$, intrabatch CV $0.8 \%$, interbatch CV $2.3 \%$.

\section{Statistical analysis}

All analysis was carried out using the statistical package STATISTICA (StatSoft Ltd, Bedford, Beds, UK), with significance levels set at $P<0 \cdot 05$. Datasets did not deviate significantly from the normal distribution (Kolmogorov-Smirnov test) and are described as mean values with their standard errors.

One-way ANOVA ( $F$ test) was applied to identify potential differences between treatment groups: where significant for post-treatment changes, anticipated effects (decrease in plasma homocysteine and increase in plasma and erythrocyte folate) were identified by the planned comparison test. The degree of association $\left(r^{2}\right)$ between baseline parameters was assessed by Pearson $r$ correlation analysis. Correlations between change and initial baseline values were examined by Bland-Altman correlation plots, where change is correlated against the average of pre- and post-intervention values.

Table 1. Baseline descriptive statistics of human volunteers randomised to four intervention treatments (about $200 \mu \mathrm{g}$ folic acid equivalents per d) for 16 weeks: (i) folate-rich foods; (ii) (6S)-5-methyltetrahydrofolic acid $\left(5-\mathrm{CH}_{3} \mathrm{H}_{4}\right.$ PteGlu) capsule; (iii) folic acid capsule; (iv) placebo capsule (Mean values with their standard errors)

\begin{tabular}{|c|c|c|c|c|c|c|c|c|c|}
\hline \multirow[b]{2}{*}{ Parameter } & \multicolumn{2}{|c|}{ Food group } & \multicolumn{2}{|c|}{ 5- $\mathrm{CH}_{3} \mathrm{H}_{4}$ PteGlu } & \multicolumn{2}{|c|}{ Folic acid } & \multicolumn{2}{|c|}{ Placebo } & \multirow{2}{*}{$\begin{array}{l}\text { ANOVA† variance } \\
\text { ratio ( } F \text { test) }\end{array}$} \\
\hline & Mean & SEM & Mean & SEM & Mean & SEM & Mean & SEM & \\
\hline Subjects $(n)$ & \multicolumn{2}{|c|}{38} & \multicolumn{2}{|c|}{42} & \multicolumn{2}{|c|}{40} & \multicolumn{2}{|c|}{43} & \\
\hline Male & \multicolumn{2}{|c|}{15} & \multicolumn{2}{|c|}{18} & \multicolumn{2}{|c|}{14} & \multicolumn{2}{|c|}{17} & \\
\hline Female & \multicolumn{2}{|c|}{23} & \multicolumn{2}{|c|}{24} & \multicolumn{2}{|c|}{26} & \multicolumn{2}{|c|}{26} & \\
\hline Age (years) & $44 \cdot 8$ & 1.9 & 44.5 & $2 \cdot 1$ & $48 \cdot 2$ & 1.9 & $45 \cdot 9$ & $2 \cdot 0$ & NS \\
\hline $\mathrm{BMI}\left(\mathrm{kg} / \mathrm{m}^{2}\right)$ & $25 \cdot 3$ & 0.6 & $25 \cdot 4$ & 0.7 & $25 \cdot 3$ & 0.6 & $26 \cdot 2$ & 0.7 & NS \\
\hline Dietary folate intake $(\mathrm{nmol} / \mathrm{d})$ & 662 & 45 & 637 & 27 & 711 & 36 & 788 & 52 & NS \\
\hline Plasma homocysteine ( $\mu \mathrm{mol} / \mathrm{l})$ & $9 \cdot 52$ & 0.55 & $10 \cdot 35$ & 0.86 & $9 \cdot 32$ & 0.41 & $9 \cdot 05$ & 0.41 & NS \\
\hline Plasma folate $(\mathrm{nmol} / \mathrm{l})$ & $24 \cdot 5$ & $2 \cdot 3$ & $21 \cdot 7$ & 1.6 & $24 \cdot 1$ & 2.4 & $25 \cdot 7$ & $2 \cdot 1$ & NS \\
\hline Erythrocyte folate (nmol/l) & 872 & 61 & 793 & 42 & 833 & 56 & 895 & 60 & NS \\
\hline
\end{tabular}

†One-way ANOVA ( $F$ test); $P<0.05$ considered to be significant. 


\section{Results \\ Compliance}

A total of 163 volunteers successfully completed the study from an initial 181 volunteers who provided a pre-intervention baseline sample. Of those that did not complete, eight volunteers withdrew for personal reasons, and ten volunteers were excluded for subsequently being prescribed medication that fell within the study exclusion criteria. Of those volunteers completing the study, eleven had recently been taking B vitamin or folic acid supplements and were delayed from undergoing pre-study screening for at least a $120 \mathrm{~d}$ washout period: two in the food group, five in the $5-\mathrm{CH}_{3} \mathrm{H}_{4} \mathrm{PteGlu}$ group, and four in the folic acid group. Capsule compliance was calculated from counting back the capsules left over at the end of each 4-weekly delivery period and cross-checking with a compliance tick-sheet, and was approximately $96 \%$ for each supplement group (folic acid, 5- $\mathrm{CH}_{3} \mathrm{H}_{4}$ PteGlu and placebo). Food group compliance was assessed by increase in dietary folate intake.

\section{Baseline data}

There were no significant differences between any of the treatment groups for age, BMI, plasma homocysteine, plasma folate, erythrocyte folate or dietary folate intake (Table 1), nor in intake of folate metabolism-related vitamins $B_{2}, B_{6}$ and $\mathrm{B}_{12}$. Average intake of folate was approximately $700 \mathrm{nmol} / \mathrm{d}$, i.e. $154 \%$ of the UK reference nutrient intake (RNI) which is defined as the amount above which an intake will almost certainly be adequate ${ }^{(23)}$. Average intakes of other B vitamins were $2 \mathrm{mg} / \mathrm{d}$ for vitamin $\mathrm{B}_{2}(160 \% \mathrm{RNI})$, $2.3 \mathrm{mg} / \mathrm{d}$ for vitamin $\mathrm{B}_{6}(28.8 \mu \mathrm{g} / \mathrm{g}$ protein; $190 \% \mathrm{RNI})$ and $5 \cdot 18 \mu \mathrm{g} / \mathrm{d}$ for vitamin $\mathrm{B}_{12}(345 \% \mathrm{RNI})$. Average plasma homocysteine status was approximately $9.5 \mu \mathrm{mol} / \mathrm{l}$. Although there is no consensus on cut-off points it has been argued, from modelling of folic acid supplementation-induced minimisation of plasma homocysteine, that a normal frequency distribution in folate-replete adults would have a mean of 8.3 (SD $1.7 ; 95 \%$ CI $4.9,11.7) \mu \mathrm{mol} / \mathrm{l}^{(24)}$. Average folate status (plasma approximately $24 \mathrm{nmol} / \mathrm{l}$, and erythrocyte approximately $850 \mathrm{nmol} / \mathrm{l})$ was within acceptable ranges. The acceptable cut-off for plasma folate is $>14 \mathrm{nmol} / \mathrm{l}$ (with deficiency considered to be $<7 \mathrm{nmol} / \mathrm{l}$ ), and the acceptable cut-off for erythrocyte folates is $>360 \mathrm{nmol} / \mathrm{l}$ (with deficiency considered to be $<320 \mathrm{nmol} / \mathrm{l})^{(25)}$. Baseline plasma folate associated positively with baseline erythrocyte folate $\left(P<0 \cdot 001 ; r^{2} 0 \cdot 450\right)$.

\section{Effect of intervention on plasma homocysteine, and plasma and erythrocyte folate status}

A significant increase in dietary folate intake was confined to the food group (Table 2), indicating that any increase in folate status seen in the $5-\mathrm{CH}_{3} \mathrm{H}_{4} \mathrm{PteGlu}$ and folic acid capsule intervention groups was due to the effect of the supplements, and not to dietary changes during the course of the study. The mean increase in dietary folate intake in the food group was $431 \mathrm{nmol} / \mathrm{d}$ greater that the placebo group but $412 \mathrm{nmol} / \mathrm{d}$ greater than the mean increase for all the other three treatment groups combined (approximately equal to $90 \%$ of target). When compared with the placebo group, plasma homocysteine was lowered to a similar extent in the three active intervention groups. Changes in both plasma and erythrocyte folate status were significantly greater than the placebo for food, 5- $\mathrm{CH}_{3} \mathrm{H}_{4}$ PteGlu and folic acid (Table 2), and increases due to $5-\mathrm{CH}_{3} \mathrm{H}_{4}$ PteGlu and folic acid were greater than in the food group. The mean plasma increase due to folic acid was $26 \%$ higher $(P=0.086)$ than the increase due to 5- $\mathrm{CH}_{3} \mathrm{H}_{4}$ PteGlu. The relative increase in plasma folate concentration in the food group was $31 \%$ when compared with that induced by folic acid, but $39 \%$ when compared with 5- $\mathrm{CH}_{3} \mathrm{H}_{4}$ PteGlu. The relative increase in erythrocyte folate concentration in the food group when compared with that induced by folic acid was $43 \%$, and $40 \%$ when compared with 5- $\mathrm{CH}_{3} \mathrm{H}_{4}$ PteGlu. When data for the food, folic acid and $5-\mathrm{CH}_{3} \mathrm{H}_{4} \mathrm{PteGlu}$ intervention groups were combined, a Bland-Altman correlation plot indicated a positive correlation between the change in plasma folate concentration following intervention and the baseline plasma folate concentration

Table 2. Post-supplementation changes in dietary folate intake and fasting folate status of human volunteers randomised to four intervention

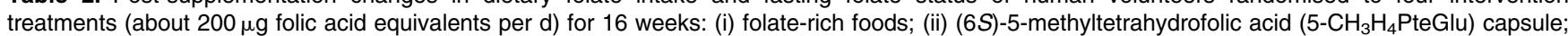
(iii) folic acid capsule; (iv) placebo capsule

(Mean values with their standard errors)

\begin{tabular}{|c|c|c|c|c|c|c|c|c|c|}
\hline \multirow[b]{2}{*}{ Parameter } & \multicolumn{2}{|c|}{ Food group } & \multicolumn{2}{|c|}{ 5- $\mathrm{CH}_{3} \mathrm{H}_{4}$ PteGlu } & \multicolumn{2}{|c|}{ Folic acid } & \multicolumn{2}{|c|}{ Placebo } & \multirow{2}{*}{$\begin{array}{l}\text { ANOVA† variance } \\
\text { ratio ( } F \text { test) }\end{array}$} \\
\hline & Mean & SEM & Mean & SEM & Mean & SEM & Mean & SEM & \\
\hline Subjects $(n)$ & \multicolumn{2}{|c|}{38} & \multicolumn{2}{|c|}{42} & \multicolumn{2}{|c|}{40} & \multicolumn{2}{|c|}{43} & \\
\hline Male & \multicolumn{2}{|c|}{15} & \multicolumn{2}{|c|}{18} & \multicolumn{2}{|c|}{14} & \multicolumn{2}{|c|}{17} & \\
\hline Female & \multicolumn{2}{|c|}{23} & \multicolumn{2}{|c|}{24} & \multicolumn{2}{|c|}{26} & \multicolumn{2}{|c|}{26} & \\
\hline Dietary folate intake (nmol/d) & $370 \cdot 2^{\mathrm{a}}$ & $36 \cdot 2$ & $-18 \cdot 8^{\mathrm{b}}$ & $25 \cdot 4$ & $-44 \cdot 4^{b}$ & $30 \cdot 8$ & $-61 \cdot 2^{b}$ & $25 \cdot 8$ & $P<0.001$ \\
\hline Plasma homocysteine ( $\mu \mathrm{mol} / \mathrm{l})$ & $-0.61^{b}$ & 0.37 & $-1 \cdot 21^{\mathrm{b}}$ & 0.46 & $-1 \cdot 21^{\mathrm{b}}$ & 0.26 & $0.38^{\mathrm{a}}$ & 0.24 & $P<0.01$ \\
\hline Plasma folate $(\mathrm{nmol} / \mathrm{l})$ & $5 \cdot 91^{\mathrm{b}}$ & $2 \cdot 17$ & $15 \cdot 10^{c}$ & 1.94 & $18 \cdot 96^{\mathrm{C} *}$ & $2 \cdot 24$ & $-0.23^{a}$ & $1 \cdot 74$ & $P<0.001$ \\
\hline $\begin{array}{l}\text { Increase in food group relative to } \\
\text { reference folates (ratio) }\end{array}$ & - & & 0.39 & & 0.31 & & - & & \\
\hline Erythrocyte folate $(\mathrm{nmol} / \mathrm{l})$ & $137^{\mathrm{b}}$ & 40 & $343^{c}$ & 33 & $321^{c}$ & 42 & $32^{\mathrm{a}}$ & 37 & $P<0.001$ \\
\hline $\begin{array}{l}\text { Increase in food group relative to } \\
\text { reference folates (ratio) }\end{array}$ & - & & 0.40 & & 0.43 & & - & & \\
\hline
\end{tabular}

${ }^{a, b, c}$ Mean values within a row with unlike superscript letters are significantly different $(P<0.05$; planned comparison test)

* The folic acid group has a trend to be higher than the $5-\mathrm{CH}_{3} \mathrm{H}_{4} \mathrm{PteGlu}$ group $(P=0.086)$.

†One-way ANOVA ( $F$ test); $P<0.05$ considered to be significant. 
$(P<0.001 ; r$ 0.269). However, this relationship was driven largely by the $5-\mathrm{CH}_{3} \mathrm{H}_{4}$ PteGlu intervention group $(P<0 \cdot 001$; $r$ 0.496). Bland-Altman correlation plots between the change in erythrocyte folate concentration and baseline erythrocyte folate concentration indicated positive correlations for the three intervention groups (food $P<0.01, r 0.410 ; 5-\mathrm{CH}_{3} \mathrm{H}_{4}$ PteGlu $P<0.01, r 0.416$; folic acid $P<0.01, r 0.408$ ). Thus, the higher the initial plasma folate or erythrocyte folate concentration, the greater the tendency for a larger increase in status following the 16-week intervention period.

\section{Discussion}

\section{Pre-intervention}

There were no significant differences between any of the treatment groups for age, BMI, plasma homocysteine, plasma folate, erythrocyte folate or dietary intakes of folate and folate metabolism-related $\mathrm{B}$ vitamins $\left(\mathrm{B}_{2}, \mathrm{~B}_{6}\right.$ and $\left.\mathrm{B}_{12}\right)$, indicating successful random group allocation. As a whole, the generally healthy volunteers selected for the four study intervention groups had good mean baseline dietary folate intakes, plasma homocysteine status, and plasma and erythrocyte folate status.

\section{Post-intervention}

The target intake of an extra $453 \mathrm{nmol} / \mathrm{d}$ of natural food folate was chosen because it was considered to be a realistic achievable and maintainable amount for a food intervention protocol. Nevertheless, some participants may have partially replaced existing folate-rich foods in their diet with the provided folate-rich foods. This may explain, in comparison with the other treatment groups combined, why the folate intake of the volunteers in our food intervention group was only approximately $90 \%$ of the target additional intake.

Plasma homocysteine concentrations were lowered moderately but significantly by all three active interventions, with no statistical difference between them in effectiveness. Folate status was raised significantly with folic acid and a nature-identical form of folate $\left(5-\mathrm{CH}_{3} \mathrm{H}_{4} \mathrm{PteGlu}\right)$, and was raised to a lesser extent by increasing the amount of naturally folate-rich foods in the diet. The increase in fasting plasma folate with folic acid showed a trend $(P=0.086)$ to be significantly greater than the increase induced by $5-\mathrm{CH}_{3} \mathrm{H}_{4}$ PteGlu. This lowered the estimation of the 'relative bioavailability' of natural food folate when based on this group's change in plasma folate compared with that induced by folic acid (31\%) rather than to $5-\mathrm{CH}_{3} \mathrm{H}_{4}$ PteGlu (39\%). It is interesting to note previously reported dietary interventions using physiological doses of folic acid or $5-\mathrm{CH}_{3} \mathrm{H}_{4} \mathrm{PteGlu}$ that also suggested a larger change in plasma folate concentration in response to folic acid than to $5-\mathrm{CH}_{3} \mathrm{H}_{4} \mathrm{PteGlu}{ }^{(26,27)}$. Compared with the trend $(P=0.086)$ for a $26 \%$ greater change in plasma folate concentration over 16 weeks with folic acid compared with $5-\mathrm{CH}_{3} \mathrm{H}_{4} \mathrm{PteGlu}$ in the present study, these previous studies (24 weeks with $100 \mu \mathrm{g} / \mathrm{d}$ intervention) indicated a change in plasma folate concentration with folic acid that was either $33 \%$ greater $^{(26)}$, or $52 \%$ greater $^{(27)}$, compared with 5- $\mathrm{CH}_{3} \mathrm{H}_{4} \mathrm{PteGlu}$. Whilst these results also did not reach statistical significance it is nevertheless arguable that these observations, in conjunction with results from the present study, collectively support our hypothesis that folic acid intervention may result in a greater change in fasting plasma folate than that induced by a nature-identical folate (for example, 5- $\mathrm{CH}_{3} \mathrm{H}_{4} \mathrm{PteGlu}$ ). Folic acid should therefore not be used as the reference folate in longer-term studies where estimates of natural food folate 'relative bioavailability' rest on comparative increases in plasma or serum folate concentrations.

When based on changes in erythrocyte folate, the present study indicated little discrepancy when estimating natural food folate 'relative bioavailability' using $5-\mathrm{CH}_{3} \mathrm{H}_{4}$ PteGlu $(40 \%)$ rather than folic acid $(43 \%)$ as the reference folate. This suggests that results from previous studies estimating food folate bioavailability relative to a reference dose of folic acid are probably valid when using a similar intervention dose and time frame. However, when using a dose of $906 \mathrm{nmol} / \mathrm{d}$, recent studies have concluded that $5-\mathrm{CH}_{3} \mathrm{H}_{4}$ PteGlu may either maintain ${ }^{(28)}$, or improve ${ }^{(29)}$, erythrocyte folate concentrations to a significantly greater extent than folic acid. Thus, in principle, it would also seem inappropriate to use folic acid as a reference folate when estimates of natural food folate 'relative bioavailability' rest on comparative increases in erythrocyte folate concentrations.

It is interesting to note, in particular, that changes in erythrocyte folate concentrations upon active water-soluble folate intervention (food, 5- $\mathrm{CH}_{3} \mathrm{H}_{4} \mathrm{PteGlu}$ or folic acid) appeared to be related to initial baseline concentrations such that the higher the initial status, the greater the change upon intervention. Although this is counterintuitive it is a phenomenon that has been reported for fat-soluble compounds such as $\alpha$-tocopherol, $\beta$-carotene and lutein ${ }^{(30)}$. This would mean that folate intervention studies in volunteers with normal baseline status would overestimate the response that is likely to be achieved in any population having a low or deficient status that may subsequently be targeted for folate supplementation.

\section{Conclusions}

Relative food folate bioavailability estimates using folic acid as the reference folate are clearly not valid when based on changes in plasma folate concentrations. When recent published observations are additionally taken into account it is also arguable that, in principle, folic acid should not be used as the reference folate even when estimates of food folate bioavailability are based on changes in erythrocyte folate concentrations. Using $(6 S)-5-\mathrm{CH}_{3} \mathrm{H}_{4} \mathrm{PteGlu}$ as the reference folate in long-term natural food folate bioavailability studies would avoid future results' validity being questioned.

\section{Acknowledgements}

The present study was financially supported by the UK Food Standards Agency with additional Central Science Grant funding by the Biotechnology and Biological Sciences Research Council. Merck-Eprova AG provided gratis coded supplement capsules of $5-\mathrm{CH}_{3} \mathrm{H}_{4} \mathrm{PteGlu}$, folic acid and placebo. The authors thank the study volunteers, staff of the Human Nutrition Unit (Aliceon Blair, Ruth Whitlam, Yvonne Clements and Trudy Harrison) and Charlotte Sayce, for general assistance and diet diary coding. 
The following are the contributions of the authors: securing funding (P. M. F. and H. J. P.); intellectual input into the study design (all authors); securing Human Research Governance and ethics approvals (P. M. F., C. A. W.); recruiting and handling volunteers, diet diary coding and preparing data (M. J. K. and C. A. W.); oversight of analysis of plasma homocysteine (H. J. P.); analysis of plasma and erythrocyte folate, and statistical analysis (A. J. A. W.); contribution to discussion and manuscript writing (M. J. K., A. J. A. W., H. J. P., P. M. F.). All authors approved the final version of the manuscript.

All authors declare that they have no conflicts of interest, nor any financial interests.

\section{References}

1. Anonymous (1991) Prevention of neural tube defects: results of the Medical Research Council Vitamin Study. Medical Research Council Vitamin Study Research Group. Lancet 338, 131-137.

2. Bazzano LA, Reynolds K, Holder KN, et al. (2006) Effects of folic acid supplementation on risk of cardiovascular diseases: a meta-analysis of randomised controlled trials. JAMA 296, $2720-2726$.

3. Malaguarnera M, Ferri R, Bella R, et al. (2004) Homocysteine, vitamin $\mathrm{B}_{12}$, and folate in vascular dementia and Alzheimer's disease. Clin Chem Lab Med 42, 1032-1035.

4. Kim Y-I (2003) Role of folate in colon cancer development and progression. J Nutr 133, 3731S-3739S.

5. Dietrich M, Brown CJ \& Block G (2005) The effect of folate fortification of cereal grain products on blood folate status, dietary folate intake and dietary folate sources among adult non-supplement users in the United States. J Am Coll Nutr 24, 266-274.

6. Lopez-Camelo JS, Orioli M, de Graca Dutra M, et al. (2005) Reduction of birth prevalence rates of neural tube defects after folic acid fortification in Chile. Am J Med Genet A 135, 120-125.

7. De Wals P, Tairou F, van Allen MI, et al. (2007) Reduction in neural tube defects after folate fortification in Canada. New Eng $J$ Med 357, 135-142.

8. McNulty H \& Pentieva K (2004) Folate bioavailability. Proc Nutr Soc 63, 529-536.

9. Sanderson P, McNulty H, Mastroiacovo P, et al. (2003) Folate bioavailability: UK Food Standards Agency workshop report. Br J Nutr 90, 473-479.

10. Steinberg SE (1984) Mechanisms of folate homeostasis. Am J Physiol 246, G319-G324.

11. Gregory JF (2001) Case study: folate bioavailability. J Nutr 131, 1376S-1382S.

12. Wright AJA, Finglas PM, Dainty JR, et al. (2003) Single oral doses of ${ }^{13} \mathrm{C}$ forms of pteroylmonoglutamic acid and 5-formyltetrahydrofolic acid elicit differences in short-term kinetics of labelled and unlabelled folates in plasma: potential problems in interpretation of folate bioavailability studies. Br J Nutr 90, 363-371.

13. Wright AJA, Finglas PM, Dainty JR, et al. (2005) Differential kinetic behaviour and distribution for pteroylmonoglutamic acid and reduced folates: a revised hypothesis of the primary site of PteGlu metabolism in humans. J Nutr 135, 619-623.

14. Wright AJA, Dainty JR \& Finglas PM (2007) Folic acid metabolism in human subjects revisited: potential implications for proposed mandatory folic acid fortification in the UK Br J Nutr 98, 667-675.

15. Herbert V (1999) Folic acid. In Modern Nutrition in Health and Disease, 9th ed., pp. 433-446 [ME Shils, JA Olson, M Shike and AC Ross, editors]. Baltimore: MD, Williams \& Wilkins.

16. Gregory JF \& Quinlivan EP (2002) In vivo kinetics of folate metabolism. Апnи Rev Nutr 22, 199-220.

17. Steinberg SE (1984) Mechanisms of folate homeostasis. Am J Physiol 246, G319-G324.

18. Kelly P, McPartlin J, Goggins M, et al. (1997) Unmetabolised folic acid in serum: acute studies in subjects consuming fortified foods and supplements. Am J Clin Nutr 65, 1790-1795.

19. Sweeney MA, McPartlin J \& Scott J (2007) Folic acid fortification and public health: report on threshold above which unmetabolised folic acid appear in serum. BMC Public Health 7, 41.

20. Food Standards Agency (2002) McCance and Widdowson's The Composition of Foods, 6th summary ed. Cambridge, UK: Royal Society of Chemistry.

21. O’Broin SO \& Kelleher B (1992) Microbiological assay on microtitre plates of folate in serum and red cells. J Clin Path 45, 344-347.

22. Wright AJA, Finglas PM \& Southon S (2000) Erythrocyte folate analysis: saponin added during lysis of whole blood can increase apparent folate concentrations, depending on hemolysate $\mathrm{pH}$. Clin Chem 46, 1978-1986.

23. Department of Health (1991) Dietary Reference Values for Food Energy and Nutrients for the United Kingdom. Report on Health and Social Subjects no. 41. London: H.M. Stationery Office.

24. Ubbink JB, Becker PJ, Vermask WJH, et al. (1995) Results of B-vitamin supplementation study used in a prediction model to define a reference range for plasma homocysteine. Clin Chem 41, 1033-1037.

25. Gibson RS (1990) Assessment of the status of folate and vitamin B-12. In Principles of Nutritional Assessment, chapter 22, pp. 461-486 [RS Gibson, editor]. Oxford: Oxford University Press.

26. Venn BJ, Green TJ, Moser R, et al. (2002) Increases in blood folate indices are similar in women of childbearing age supplemented with [6S]-5-methyltetrahydrofolate and folic acid. J Nutr 132, 3353-3355.

27. Venn BJ, Green TJ, Moser R, et al. (2003) Comparison of the effect of low-dose supplementation with L-5-methyltetrahydrofolate or folic acid on plasma homocysteine: a randomised placebo-controlled study. Am J Clin Nutr 77, 658-662.

28. Houghton LA, Sherwood KL, Pawlosky R, et al. (2006) [6S]-5methyltetrahydrofolate is at least as effective as folic acid in preventing a decline in blood folate concentrations during lactation. Am J Clin Nutr 83, 842-850.

29. Lamers Y, Prinz-Langenohl R, Bramswig S, et al. (2006) Red blood cell folate concentrations increase more after supplementation with $[6 S]-5$-methyltetrahydrofolate than with folic acid in women of childbearing age. Am J Clin Nutr 84, 156-161.

30. Olmedilla B, Granado F, Southon S, et al. (2002) A European multicentre, placebo controlled supplementation study with $\alpha$-tocopherol, carotene-rich palm oil, lutein or lycopene: analysis of serum responses. Clin Sci 102, 447-456. 